\title{
Mide Kanseri ve Preoperatif Anemi Arasındaki Iliş̧inin Değerlendirilmesi
}

\section{Evaluation of the Relationship Between Stomach Cancer and Preoperative Anemia}

\author{
Murat Can MOLLAOĞLU ${ }^{1} \mathbb{D}$, Meriç Emre BOSTANCI ${ }^{1}$ D , Kürşat KARADAYI $^{2}$
}

\author{
${ }^{1}$ Sivas Numune Hastanesi Cerrahi Onkoloji Bölümü, Sivas, TURKiYE \\ ${ }^{2}$ Sivas Cumhuriyet Üniversitesi Tıp Fakültesi Cerrahi Onkoloji Bilim Dalı , Sivas, TÜRKIYE
}

Öz.

Amaç: Kanser hastalarının preoperatif en sık görülen klinik problemlerinden biri preoperatif anemidir. Preoperatif aneminin en sık görüldüğü kanser türlerinden biri mide kanseridir. Fakat mide kanserinin anemi ile ilişkisi net değildir. Bu çalıșmanın amacı mide kanserli hastalarda bağımsız prognostik risk faktörü olan patolojik evre ve tümör boyutunu ameliyat öncesi hgb (hemoglobin) değeriyle karşılaştırarak, preoperatif anemi ile tümör boyutu ve tümör evresi arasındaki ilişkiyi incelemek ve prognostik belirteçleri zayıf olan mide kanseri için preoperatif aneminin prognostik değerini araştırmaktır.

Materyal ve Metod: Sivas Cumhuriyet Üniversitesi Tıp Fakültesi Cerrahi Onkoloji bölümünde 1 Ocak 2017 ile 1 Aralık 2019 yılları arasında mide kanseri dolayısıyla küratif D2 gastrektomi ve Ro rezeksiyon uygulanmış hastaların klinikopatolojik ve demografik özellikleri retrospektif olarak incelendi.

Bulgular: Toplam 85 hasta incelendi. Hastaların $66(\% 77,6)$ 'sı erkek $19(\% 22,4)^{\prime}$ u kadındı. Hastaların yaş ortalaması $68,1(41-87)$ idi. $55(\% 64,7)$ hastaya total gastrektomi $30(\% 35,2)$ hastaya subtotal gastrektomi uygulandı. Hastaların tümü adenokarsinom tanılı idi. Hastaların 48(\%56,5)'i evre 3, 29(\%34,1)'u evre 2, 8(\%9,4)'i evre 1 idi. 51(\%60) hastanın tümör boyutu büyük 34(\%40) hastanın küçüktü. 51(\%60) hastanın anemisi (kadınlarda hgb $<110 \mathrm{~g} / \mathrm{L}$

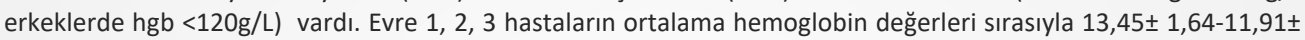
$2,18-10,29 \pm 1,68$ olarak tespit edildi. Tümör boyutu küçük hastaların $(<5 \mathrm{~cm}$ )ortalama hgb değerleri $12,88 \pm 1,5$, tümör boyutu büyük $(\geq 5 \mathrm{~cm})$ hastaların ortalama hgb değeri $9.97 \pm 1,63$ olarak tespit edildi.

Sonuç: Preoperatif anemisi bulunan mide kanserli hastaların tümör boyutları daha büyük ve ileri evre tümörlerdir. Mide kanserli hastaların tedavisi planlanırken preoperatif anemisi bulunan hastaların tümör özelliklerinin daha agresif olabileceği gözardı edilmememidir.

Anahtar Kelimeler: Preoperatif anemi, Mide Kanseri, Hemoglobin

Abstract

Background: One of the most common preoperative clinical problems of cancer patients is preoperative anemia and one of the most common types of cancer with preoperative anemia is stomach cancer. However, the relationship between stomach cancer and anemia is not clear. The aim of this study is to examine the relationship between preoperative anemia and tumor size and tumor stage by comparing the pathological stages and tumor sizes, which are independent prognostic risk factors, with preoperative hgb (hemoglobin) values, and to investigate the prognostic value of preoperative anemia for gastric cancer with poor prognostic markers.

Materials and Methods: The clinicopathological and demographic characteristics of patients who underwent curative D2 gastrectomy and R0 resection due to gastric cancer between January 1, 2017 and December 1, 2019 in Cumhuriyet University Department of Surgical Oncology were retrospectively analyzed.

Results: A total of 85 patients were examined. $66(77,6 \%)$ of the patients were male and $19(22,4 \%)$ were female. Total gastrectomy was performed in $55(64,7 \%)$ patients and $30(35,2 \%)$ patients underwent subtotal gastrectomy. All patients were diagnosed with adenocarcinoma. $48(56,5 \%)$ of the patients were stage $3,29(34,1 \%)$ were stage $2,8(9,4 \%)$ were stage 1 . Tumor size of $51(60 \%)$ patients was large and $34(40 \%)$ patients were small. $51(60 \%)$ patients had anemia (hgb $<110 \mathrm{~g} / \mathrm{L}$ in women $\mathrm{hgb}<120 \mathrm{~g} / \mathrm{L}$ in men). Mean hemoglobin values of Stage 1, 2, 3 patients were detected $13,45 \pm 1,64-11,91 \pm 2,18-10,29 \pm 1,68$ respectively. The mean hgb value of the patients with small tumor size $(<5 \mathrm{~cm})$ was $12.88 \pm 1,5$, and the mean $\mathrm{hgb}$ value of the patients with large tumor size $(\geq 5 \mathrm{~cm})$ was $9.97 \pm$ 1,63 .

Conclusion: The tumor size of gastric cancer patients with preoperative anemia is larger and their tumors are advanced. When planning the treatment of patients with gastric cancer, it should not be overlooked that patients with preoperative anemia may have more aggressive tumor characteristics.

Key words: Preoperative anemia, Stomach Cancer, Hemoglobin
Sorumlu Yazar/Corresponding Author

Dr. Murat Can MOLLAOĞLU Sivas Cumhuriyet Üniversitesi Tıp Fakültesi Cerrahi Onkoloji Bilim Dalı Sivas Numune Hastanesi Cerrahi Onkoloji Bölümü Sivas, TÜRKIYE

E-mail:drmcm_12@hotmail.com Geliş tarihi / Received: 19.03.2021 Kabul tarihi / Accepted: 09.07.2021 DOI: $10.35440 /$ hutfd. 897403 


\section{Giriş}

Mide kanseri Dünya çapında en sık görülen dördüncü kanser çeşidi ve dünya çapında kansere bağlı ölümlerin en sık ikinci nedenidir (1). Radyoterapi, kemoterapi ve immünoterapi gibi tedavi seçeneklerinin hızla gelişmesine rağmen, cerrahi rezeksiyon mide kanseri için en doğru tedavi seçeneğidir $(2,3)$. Mide kanseri ile ilgili bazı nedensel faktörler belirlenmiş olmasına rağmen etiyolojisi ve patogenezi henüz tam olarak belirlenememiştir. Mide kanserini önleme ve mide kanserinden korunma sorun olmaya devam etmektedir (4). Mide kanserinin tanı ve tedavi stratejilerindeki ilerlemelere rağmen $(5,6)$, mide kanserli hastalarının çoğunda 5 yıllık sağkalım oranı \% 20'den düşüktür. Hastalar kötü prognostik faktörler olan metastaz ve nüksle başvururlar $(7,8)$.

Mide kanserinde mortalite oranını azaltmak için prognostik risk faktörleri belirlenmeli kanser kontrol altına alınmaya çalışılmalı ve bireyselleştirilmiş tedaviler planlanarak en etkili tedavi seçeneği seçilmelidir (9-11). Bu nedenle, yüksek risk grubunu seçmek için prognostik faktörleri belirlemeye yönelik çabalar devam etmektedir.

Tam prognostik bilgi sağlamamasına rağmen mide kanserinin en önemli prognostik faktörlerinden biri Tümör Nod metastaz (TNM) evreleme sistemidir (12). Tümör boyutu, prognoz üzerindeki etkisinden dolayı birçok solid tümörün "T" evresi olarak kabul edilmiştir. Son zamanlarda, birçok çalışma, tümör boyutunun invazyon derinliği ve lenf nodu metastazı ile ilişkili olduğunu ve bunun mide kanseri hastalarında bağımsız bir prognostik risk faktörü olduğunu ortaya koymuştur (13-17).

Tümör türüne ve hastalığın evresine göre oranı değişmekle beraber birçok kanser hastasında en sık görülen hematolojik bozukluk anemidir. Kanserli hastalarının \%30 ile \%90' arasındaki hasta grubunda tanı konulduğunda anemi de beraberinde görülmektedir $(18,19)$. Preoperatif anemi hastaların yaşam kalitesini olumsuz yönde etkilemektedir. Aynı zamanda preoperatif aneminin ürotelyal, laryngeal ve kolorektal kanser türü için kötü bir prognostik risk faktörü olduğu bulunmuştur (20-22).

Son zamanlarda, mide kanserinin prognozunu değerlendirmek ve tahmin etmek için bazı hematolojik biyobelirteçler kullanılmaya başlandı. Bu biyobelirteçler kullanışlı kolay ulaşılabilinen ve uygun maliyetli olduğu için kısa sürede çekici bir araştırma haline geldi. Bu anlamda yapılan çeşitli klinik çalışmalar, nötrofil-lenfosit oranı ve trombosit-lenfosit ve monosit lenfosit oranının mide kanserinin prognozu ile ters orantılı olduğunu bildirdi $(23,24)$. Biz kendi çalışmamızda hematolojik biyobelirteç olarak hgb (hemoglobin)' i kullanmayı tercih ettik.

Ulusal Kanser Enstitüsü (National Cancer Institute) tarafından önerilen kriterlere ve Çin Klinik Onkoloji Derneği (Chinese Society of Clinical Oncology) (CSCO) tarafından yayınlanan klinik uygulama kılavuzlarına dayanarak, anemi erkeklerde preoperatif hgb düzeyi $<120 \mathrm{~g} / \mathrm{L}$ ve kadınlarda $<110$ g / L olarak tanımlanır (25).
Mide kanserinde preoperatif anemi yaygın bir hematolojik hastalık olmasına rağmen mide kanseri hastaları için prognostik değer taşıyıp taşımadığı hala netlik kazanmamıştır. Bu nedenle, biz de bu çalışmada, preoperatif anemi ile mide kanserinin TNM evrelemesi ve tümör boyutu arasındaki ilişkiyi değerlendirmeyi amaçladık.

\section{Materyal ve Metod}

Sivas Cumhuriyet Üniversitesi Tıp Fakültesi Cerrahi Onkoloji Bölümünde 1 Ocak 2017 ile 1 Aralık 2019 yılları arasında mide kanseri dolayısıyla küratif D2 gastrektomi ve Ro rezeksiyon uygulanmış hastaların klinikopatolojik ve demografik özellikleri retrospektif olarak incelendi. Hasta bilgilerine bilgisayar ve dosya kayıtlarından ulaşıldı. Hastaların TNM sınıflaması, patolojik tanıları tümör boyutu yaşları cinsiyetleri ve operasyon öncesi serum hemoglobin değerleri incelendi. Tümör evresi ile tümör boyutları ve serum hemoglobin değerleri karşılaştırıldı. Tümör boyutu için kesme değer $5 \mathrm{~cm}$ olarak belirlendi. $5 \mathrm{~cm}$ ve üzeri tümörler büyük $5 \mathrm{~cm}^{\prime}$ in altındaki tümörler küçük olarak belirlendi (17). Kadınlar için serum hgb değerinin kesme değeri $110 \mathrm{~g} / \mathrm{L}$ erkekler için $120 \mathrm{~g} / \mathrm{L}$ olarak belirlendi. Serum hgb değeri bu değerlerin altında olan hastalar anemik kabul edildi. Tümör evrelemesi, Amerikan Ortak Kanser Komitesi(American Joint Committee on Cancer) (AJCC) tümörnod-metastaz (TNM) sınıflandırmasının yedinci baskısına göre yapıldı (26) .Sivas Cumhuriyet Üniversitesi Girişimsel Olmayan Klinik Araştırmalar Etik Kurulu'ndan 10.03.2021 tarihli 2021-03/24 karar no'lu etik kurul onayı alınmıştır.

\section{Istatistiksel değerlendirme Evren ve örneklem seçimi}

1 ocak 2017 ile 1 aralık 2019 tarih aralığında Sivas Cumhuriyet Üniversitesi Tıp Fakültesi Cerrahi Onkoloji bilim daIında mide kanseri nedeniyle küratif D2 gastrektomi ve Ro rezeksiyon uygulanmış hastaların tüm hasta dosyaları geriye dönük incelendi.

\section{istatistiksel Analiz}

Veriler SPSS (statistical package fort the social sciences) (ver:22) paket programına girildi. Çalışmada kullanılan verilerin normallik sıralaması Shapiro-Wilk testiyle gerçekleştirildi. Normallik sıralamasının sağlanmadığı durumda; ikili karşılaştırmalarda Mann whitney U testi, çoklu karşılaştırmalarda ise Kruskal Wallis $\mathrm{H}$ testi kullanıldı. Normallik sıralamasının sağlandığı durumda; ikili karşılaştırmalarda Student t testi, çoklu karşılaştırmalarda ise ANOVA testi kullanıldı. Analiz sonuçları \%95 güven seviyesinde yorumlandı.

\section{Bulgular}

Toplam 85 hasta incelendi. Hastaların $66(\% 77,6)$ 'sı erkek $19(\% 22,4)^{\prime}$ u kadındı. Hastaların yaş ortalaması 68,1(41$87)$ idi. 55(\%64,7) hastaya total gastrektomi $30(\% 35,2)$ hastaya subtotal gastrektomi uygulandı. Hastaların tümü adenokarsinom tanılı idi. Hastaların 48(\%56,5)'i evre 3, $29(\% 34,1)$ 'u evre $2,8(\% 9,4)^{\prime}$ i evre 1 idi. 
Alt gruplar incelendiğinde hastaların 26(\%30,6)'sı 3c $11(\% 12,9)^{\prime} i \quad 3 b, \quad 11(\% 12,9)^{\prime} i \quad 3 a, \quad 14(16,5)^{\prime}$ ü $2 b$, $15(\% 17,6)^{\prime} 2 a, 2(\% 2,4)^{\prime}$ si $1 b, 6(\% 7,1)^{\prime}$ sı 1 a olduğu görüldü. $51(\% 60)$ hastanın tümör boyutu büyük 34(\%40) hastanın küçüktü.51(\%60) hastanın anemisi vardı.

Evre 1, 2, 3 hastaların ortalama hemoglobin değerleri sıra-

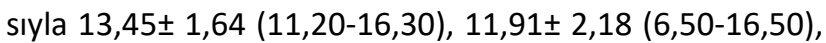
$10,29 \pm 1,68(6,20-14,00)$ olarak tespit edildi. Sonuçlar kendi aralarında anlamlı bulundu. Hastaların evreleri ile hgb değerleri arasında ters bir ilişki tespit edildi. Anemisi olan hastaların tümör evrelerinin daha büyük olduğu görüldü (Tablo 1 ).

Tablo 1. Tümörün evresi ve hemoglobin $(\mathrm{g} / \mathrm{dL})$ değerlerinin karşılaştırılması

\begin{tabular}{lccc}
\hline Evre & Min -Max & Mean \pm SD & $\boldsymbol{P}$ \\
\hline Evre 1 & $11,2-16,3$ & $13,45 \pm 1,64$ & $<0,001$ \\
Evre 2 & $6,5-16,5$ & $11,91 \pm 2,18$ & $<0,001$ \\
Evre 3 & $6,2-14$ & $10,29 \pm 1,68$ & $<0,001$ \\
\hline SD: Standart Deviation & &
\end{tabular}

SD: Standart Deviation

Alt gruplar kendi aralarında karşılaştırıldığında evre $1 a, 1 b$, $2 a, 2 b, 3 a, 3 b, 3 c$ 'nin ortalama hgb değerleri sırasıyla $13,08 \pm 1,38(11,2-14,9), 14,55 \pm 2,47(12,8-16,3), 11,85 \pm$ $2,05(7,3-14,9), 11,96 \pm 2,39(6,5-16,5), 10,35 \pm 1,54(6,6-$ $12,1), 10,24 \pm 1,71(8-14), 10,28 \pm 1,79(6,2-13,8)$ olarak tespit edildi. Bu değerler kendi aralarında anlamsız bulundu. Alt gruplar ile hgb değeri arasında bir ilişki kurulamadı (Tablo 2).

Tablo 2. Tümörün alt grup evreler ile hemoglobin $(\mathrm{g} / \mathrm{dL})$ değerlerinin karşılaştırılması.

\begin{tabular}{llll}
\hline Evre & Min - Max & Mean \pm SD & $p$ \\
\hline 1a & $11,2-14,9$ & $13,08 \pm 1,38$ & 0,001 \\
1b & $12,8-16,3$ & $14,55 \pm 2,47$ & 0,001 \\
2a & $7,3-14,9$ & $11,85 \pm 2,05$ & 0,001 \\
2b & $6,5-16,5$ & $11,96 \pm 2,39$ & 0,001 \\
3a & $6,6-12,1$ & $10,35 \pm 1,54$ & 0,001 \\
3b & $8-14$ & $10,24 \pm 1,71$ & 0,001 \\
3c & $6,2-13,8$ & $10,28 \pm 1,79$ & 0,001 \\
\hline SD: Standart Deviation & &
\end{tabular}

Tümör boyutu küçük hastaların ortalama hgb değerleri $12,88 \pm 1,5(9,20-16,50)$, tümör boyutu büyük hastaların ortalama hgb değeri $9,97 \pm 1,63(14,00-6,20)$ olarak tespit edildi. Sonuçlar anlamlı bulundu. Pre operatif anemisi bulunan hastaların tümör boyutunun da büyük olduğu gözlendi (Tablo3).

Tablo 3. Tümör boyutu ve Hemoglobin $(g / d L)$ değerinin karşılaştırılması

\begin{tabular}{llll}
\hline Boyut & Min - Max & Mean \pm SD & $\boldsymbol{p}$ \\
\hline Küçük $(\mathrm{cm})$ & $9,2-16,5$ & $12,88 \pm 1,5$ & \\
Büyük $(\mathrm{cm})$ & $6,2-14$ & $9,97 \pm 1,63$ & $<0,001$ \\
\hline SD: Standart Deviation & & $<0,001$ \\
\hline
\end{tabular}

Evre 1,2,3 hastaların ortalama tümör boyutları sırasıyla, $3,25 \pm 1,5(2,25-3,75), 4,20 \pm 3,5(3,50-7,00), 6,25 \pm 4,5(5,50-$
$10,00)$ olarak tespit edildi. Sonuçlar kendi aralarında anlamlı bulundu. Tümör boyutu ile tümör evresi arasında doğru bir orantı tespit edildi. Tümör boyutu büyük olan hastaların daha ileri evre oldukları görüldü (Tablo 4).

Tablo 4. Tümörün evresi ve tümör boyutunun $(\mathrm{cm})$ karşılaştırılması.

\begin{tabular}{lccccc}
\hline Evre & Percentile 25 & Percentile 75 & Median & IQR & $\boldsymbol{p}$ \\
\hline & & & & & \\
Evre 1 & 2,25 & 3,75 & 3,25 & 1,5 & $<0,001$ \\
Evre 2 & 3,5 & 7 & 4,2 & 3,5 & $<0,001$ \\
Evre 3 & 5,5 & 10 & 6,25 & 4,5 & $<0,001$ \\
\hline IQR $:$ interquartile Range & & & &
\end{tabular}

Kadın hastalarda ortalama hgb değeri 10,31 $\pm 1,85(6,60$ $13,50)$, erkek hastalarda ortalama hgb değeri $11,37 \pm$ 2,15(6,20-16,50) olarak hesaplandı. Fakat değerler kendi arasında anlamsız bulundu. Preoperatif aneminin hastanın cinseyetiyle alakalı olmadığı gözlendi (Tablo 5).

Tablo 5. Mide kanserli hastaların cinsiyetlerinin hemoglobin $(\mathrm{g} / \mathrm{dL})$ değerleriyle karşılaştırılması

\begin{tabular}{lccc}
\hline Cinsiyet & Min - Max & Mean \pm SD & $\boldsymbol{p}$ \\
\hline Kadın & $6,6-13,5$ & $10,31 \pm 1,85$ & 0,054 \\
Erkek & $6,2-16,5$ & $11,37 \pm 2,15$ & 0,054 \\
\hline SD:
\end{tabular}

SD: Standart Deviation

\section{Tartışma}

Anemi kanser hastalarında preoperatif sık görülen sorunlardan biridir. Kanser hastalarında preoperatif aneminin birçok sebebi olduğundan hastaların klinik özelliklerinin iyi araştırılması gereklidir $(18,27)$. Demir eksikliği, folik asit eksikliği, kemik iliği tutulumu, tümöre bağlı kanama kansere bağlı aneminin önemli nedenlerindendir (28). Kanserli hastalarda preoperatif anemi, hastaların prognozunu olumsuz etkiler ve yaşam kalitesini düşürür. Yani kanserli hastalarda preoperatif anemi ile prognoz ve yaşam kalitesi ters orantılıdır (29). Fakat bu konu ile ilgili birçok çalışma yapılmış olmasına rağmen preoperatif aneminin mide kanseri hastalarındaki prognostik önemi konusunda net bir sonuca varılamamıştır. Bu nedenle biz de preopereatif anemi ve mide kanseri için prognostik değere sahip TNM evrelemesi ve tümör boyutu arasındaki ilişkiyi değerlendirdik.

Kanser hastalarında anemi prevalansı ve insidansı yüksektir. Preoperatif anemi hastalarının performansı düşüktür ve tedavi edilmesi oldukça zordur. Tüm bu olumsuzlukların hastanın prognozunu kötü etkilediği düşünülmektedir. Mide kanserli 13,154 hastanın incelendiği Huang ve arkadaşları tarafından yapılan geniş çaplı bir meta analizde preoperatif anemili hastaların prognozunun daha kötü olduğu görüldü (30). Preoperatif anemisi bulunan hastalarda prognozun kötü olmasını açıklayacak mekanizmaları araştırmak için birçok çalışma yapılmıştır.

Yapılan çalışmalar, tümör hipoksisinin indüklenebilir faktör-1 (HIF-1) ekspresyonunu ve transkripsiyonunu indüklediğini $(31,32)$, indüklenen HIF-1 in epidermal büyüme faktörü, , vasküler endotelyal büyüme faktörü, glukoz taşıyıcıları, glikolitik enzimler ve eritropoietin gibi birçok hedef 
geni aktifleştirdiği ve düzenlediğini, bu şekilde tümör proliferasyonunun arttığı, tümör invazyonu ve uzak metaztazın kolaylaştığını gösterdi $(31,33)$. Preoperatif anemisi bulunan kanser hastalarının oksijen üretimi ve tüketimi arasındaki dengesizlik nedeniyle dokunun yeterli oksijenasyonu sağlanamaz ve doku hipoksik kalır. Sonuç olarak tedaviye direnç artar ve anemili hastaların prognozu daha kötü olur (32). Yapılan bazı çalışmalar, hipoksinin tümör hücrelerinde genetik değişikliklere ve klonal seleksiyona yol açtığı ve bu yolla tümör hücresinin malignite potansiyelini arttırdığını gösterdi (33). Mide kanserinde anemi ile kötü prognoz arasındaki ilişkinin altında yatan mekanizmaları aydınlatmak için ileride yapılacak çalışmalara ihtiyaç vardır.

Mide kanserli hastalarda hgb seviyesi $10 \mathrm{~g} / \mathrm{dL}^{\prime}$ nin altına düştüğünde tedavi etkinliği azalır ve prognoz kötüleşir (32). (European Cancer Anaemia Survey) Avrupa Kanser Anemi Araştırmasından elde edilen veriler, düşük hemoglobin seviyeleri olan hastaların performanslarının daha kötü olduğunu gösterdi (34). Klinik uygulamada preoperatif hgb seviyeleri, hastanın kan transfüzyonu ihtiyacı olduğunu öngerebilir. Fakat yapılan kan transfüzyonunun kanser hastalarının prognozunu değiştirip değiştirmediği hala netlik kazanmış bir konu değildir. Yapılan birçok çalışmada anemik hastalarda kan transfüzyonun hastanın klinik sonuçlarını düzeltmediği görülmüş hatta kötü klinik sonuçlarla ilişkilendirilmiştir $(35,36)$. Kan transfüzyonun yan etkilerinin bulunduğu ve postoperatif komplikasyonları arttırdığı gösterilmiştir (37). Liu ve arkadaşlarının yapmış olduğu çalışmada perioperatif transfüzyonunun surviyi (Overall survival) çok etkilemediği görüldü (38). Bu sebeple preoperatif anemisi bulunan kanser hastalarında erken kan transfüzyonu konusunda yeni çalışmalara ihtiyaç vardır. Bizim kliniğimizde hgb düzeyi $10 \mathrm{~g} / \mathrm{dL}$ den az olan hastalara kan transfüzyonu yapıldı.

TNM evresi, mide kanserinin en iyi bağımsız prognostik risk faktörü olarak kabul edilir. Fakat yapılan bazı araştırmalar mide kanseri için TNM sınıflaması dışında bazı klinik ve patolojik faktörlerin de etkili olduğunu gösterdi. (13-17).

Zu ve arkadaşlarının yapmış olduğu çalışma tümör boyutunun mide kanseri için bağımsız bir prognostik risk faktörü olduğunu gösterdi. $5 \mathrm{~cm}$ 'den küçük tümör boyutunun iyi 5 ve $5 \mathrm{~cm}$ 'den büyük tümör boyutunun kötü prognozla ilişkili olduğunu gösterdi (17). Im ve ark. İleri evre mide kanserinde tümör boyutunu, seroza invazyonundan bağımsız olarak bir risk faktörü olarak belirledi (14). Yapılan bazı araştırmalar büyük boyutlu tümörlerin küçük boyutlu tümörlere göre survilerinin (Overall survival) daha kötü olduğunu gösterdi. $(13,15,16)$.

Mide kanseri dolayısıyla küratif cerrahi uygulanan 1688 hasta ile Kore'de yapılan bir çalışmada, ameliyat öncesi aneminin TNM evrelemesine göre evre 1-2 mide kanseri hastaları için bağımsız bir prognostik faktör olduğu sonucuna varıldı (39). Aynı çalışmada anemili hastalarının lenf nodu metastazı oranının yüksek olduğu ve tümör boyutu oranınn arttığı sonucuna varılmıştır. Mide kanseri dolayısıyla küratif cerrahi uygulanmış 2163 hastanın incelendiği Liu ve arkadaşlarının yapmış olduğu bir çalışmada preoperatif aneminin TNM evre 3 hastalarda bağımsız prognostik risk faktörü olduğu ancak TNM evre 1-2 hastalar için prognostik risk faktörü olmadığı gösterildi (38). Aynı çalışmada preoperatif anemi tümör boyutu arasında bir ilişki olduğu ve anemili hastaların tümör boyutunun daha büyük olduğu görüldü. Tümör boyutu büyüklüğü katabolik mekanizmaları tetikler malnutrisyona sebep olur ve kanama ihtimalini arttırır (34). Dolayısıyla hastanın hem fiziksel performansının düşmesine hem de organ fonksiyonlarının azalmasına sebep olur (28). Bu nedenle preoperatif anemi tümör yükünün fazlalığı ve tümörün agresif davranma potansiyelini tahmin etmek için önemli bir faktör olabilir.

Bizim çalışmamızdaki hastaların \%60'ında preoperatif anemi mevcuttu. Anemi ile tümör boyutunun, ve tümör evresinin birbirleriyle ilişkili olduğu ve bu ilişkinin negatif korelasyon şeklinde olduğu görüldü.

Bu çalışmamızı kısıtlayan bazı parametreler vardır. Birincisi tek merkezli olması ikincisi az hasta sayısıyla yapılması üçüncüsü retrospektif bir çalışma olması ve bu sebeple postoperatif takibinin ve sağ kalım süresinin değerlendirilmemesidir.

Preoperatif anemili mide kanserli hastaların tümör boyutu daha büyük ve ileri evre tümörlerdir. Bu nedenle, mide kanseri için ameliyat öncesi anemi, tümörün patolojik özelliklerini, klinik özelliklerini öngörmemizi ve buna göre tedavi protokolünü düzenlememizi sağlayabilir. Preoperatif aneminin bağımsız prognostik bir risk faktörü olarak kullanılabilmesi için ileriye dönük çalışmalara ihtiyaç vardır.

Etik onam: Sivas Cumhuriyet Üniversitesi Girişimsel Olmayan Klinik Araştırmalar Etik Kurulu'ndan 10.03.2021 tarihli 2021-03/24 karar no'lu etik kurul onayı alınmıştır.

\section{Yazar Katkıları:}

Konsept: MC.M.

Literatür Tarama: ME.B.

Tasarım: MC.M

Veri toplama: MC.M

Analiz ve yorum: $K . K$

Makale yazımı: ME.B

Eleştirel incelenmesi: K.K

Çıkar Çatışması: Herhangi bir çıkar çatışmamız bulunmamaktadir.

Finansal Destek: Araştırma kapsamında herhangi bir kurum ya da kuruluştan finansal destek sağlanmamıştır.

\section{Kaynaklar}

1. Siegel RL, Miller KD, Jemal A. Cancer statistics, 2021. CA: a cancer journal for clinicians. 2021;69(1):7-34.

2. Das M. Neoadjuvant chemotherapy: survival benefit in gastric cancer. The Lancet Oncology. 2017;18(6):e307.

3. L $X$, Zhang L, Huang R, Song W. A clinical exploration of neoadjuvant chemotherapy with tegafur, gimeracil, and oteracil potassium capsules combined with oxaliplatin for advanced gastric cancer. International journal of clinical 
and experimental medicine. 2015;8(10):19030.

4. Zhang $X-y$, Zhang P-y. Gastric cancer: somatic genetics as a guide to therapy. Journal of Medical Genetics. 2017;54(5):305-12.

5. Lordick F, Kang Y-K, Chung H-C, Salman P, Oh SC, Bodoky $G$, et al. Capecitabine and cisplatin with or without cetuximab for patients with previously untreated advanced gastric cancer (EXPAND): a randomised, open-label phase 3 trial. The lancet oncology. 2013;14(6):490-9.

6. Waddell T, Chau I, Cunningham D, Gonzalez D, Okines AFC, Wotherspoon A, et al. Epirubicin, oxaliplatin, and capecitabine with or without panitumumab for patients with previously untreated advanced oesophagogastric cancer (REAL3): a randomised, open-label phase 3 trial. The lancet oncology. 2013;14(6):481-9.

7. Blakely AM, Miner TJ. Surgical considerations in the treatment of gastric cancer. Gastroenterology Clinics. 2013;42(2):337-57.

8. Tan VP, Wong BC. Gastric cancer chemoprevention: the current evidence. Gastroenterology Clinics. 2013;42(2):299-316.

9. Hartgrink HH, Jansen EP, van Grieken NC, van de Velde CJ. Gastric cancer. The Lancet. 2009;374(9688):477-90.

10. Roukos DH, Kappas AM. Perspectives in the treatment of gastric cancer. Nature Clinical Practice Oncology. 2005;2(2):98-107.

11. Shiozaki H, Shimodaira Y, Elimova E, Wadhwa R, Sudo K, Harada $\mathrm{K}$, et al. Evolution of gastric surgery techniques and outcomes. Chinese journal of cancer. 2016;35(1):69.

12. Edge SB, Compton CC. The American Joint Committee on Cancer: the 7th edition of the AJCC cancer staging manual and the future of TNM. Annals of surgical oncology. 2010;17(6):1471-4.

13. Hosoda K, Yamashita K, Katada N, Moriya H, Mieno H, Sakuramoto $\mathrm{S}$, et al. Preoperative tumor size is a critical prognostic factor for patients with Borrmann type III gastric cancer. Surgery today. 2015;45(1):68-77.

14. Im WJ, Kim MG, Ha TK, Kwon SJ. Tumor size as a prognostic factor in gastric cancer patient. Journal of gastric cancer. 2012;12(3):164-72.

15. Quan J, Zhang R, Liang $H$, Li F, Liu $H$, Zhang $H$, et al. The impact of tumor size on survival of patients with PT4aNOMO gastric cancer. The American Surgeon. 2013;79(3):328.

16. Zhao $L-Y$, Chen X-L, Wang $Y-G$, Xin $Y$, Zhang W-H, Wang $Y$ $S$, et al. A new predictive model combined of tumor size, lymph nodes count and lymphovascular invasion for survival prognosis in patients with lymph node-negative gastric cancer. Oncotarget. 2016;7(44):72300.

17. Zu H, Wang F, Ma $Y$, Xue $Y$. Stage-stratified analysis of prognostic significance of tumor size in patients with gastric cancer. PloS one. 2013;8(1):e54502.

18. Knight K, Wade S, Balducci L. Prevalence and outcomes of anemia in cancer: a systematic review of the literature. The American journal of medicine. 2004;116(7):11-26.

19. Tas F, Eralp Y, Basaran M, Sakar B, Alici S, Argon A, et al. Anemia in oncology practice: relation to diseases and their therapies. American journal of clinical oncology. 2002;25(4):371-9.

20. Gierth M, Mayr R, Aziz A, Krieger S, Wullich B, Pycha A, et al. Preoperative anemia is associated with adverse outcome in patients with urothelial carcinoma of the bladder following radical cystectomy. Journal of cancer research and clinical oncology. 2015;141(10):1819-26.

21. Janssens GO, Rademakers SE, Terhaard CH, Doornaert PA, Bijl HP, van den Ende $P$, et al. Improved recurrence-free survival with ARCON for anemic patients with laryngeal cancer. Clinical cancer research. 2014;20(5):1345-54.

22. Qiu M-z, Yuan Z-y, Luo H-y, Ruan D-y, Wang Z-q, Wang F$h$, et al. Impact of pretreatment hematologic profile on survival of colorectal cancer patients. Tumor Biology. 2010;31(4):255-60.

23. Song S, Li C, Li S, Gao H, Lan X, Xue Y. Derived neutrophil to lymphocyte ratio and monocyte to lymphocyte ratio may be better biomarkers for predicting overall survival of patients with advanced gastric cancer. OncoTargets and therapy. 2017;10:3145.

24. Sun X, Liu X, Liu J, Chen S, Xu D, Li W, et al. Preoperative neutrophil-to-lymphocyte ratio plus platelet-to-lymphocyte ratio in predicting survival for patients with stage III gastric cancer. Chinese journal of cancer. 2016;35(1):57.

25. Clinical practice guidelines on cancer-related anemia (2012-2013 Edition). Chinese clinical oncology. 2012;1(2):18.

26. Washington $\mathrm{K}$. of the AJCC cancer staging manual: stomach. Annals of surgical oncology. 2010;17(12):3077-9.

27. Griniatsos J, Papaconstantinou I, Felekouras E, Michail P, Bakoyiannis C, Bramis J. The significance of perioperative anemia in patients with resectable gastrointestinal tract tumors. Journal-Balkan Union Of Oncology. 2004;9:24754.

28. Birgegård $G$, Aapro $M S$, Bokemeyer $C$, Dicato $M$, Drings $P$, Hornedo J, et al. Cancer-related anemia: pathogenesis, prevalence and treatment. Oncology. 2005;68(Suppl. 1):3-11.

29. Wilson $M$, Van Haaren $M$, Harlaar JJ, Park HC, Bonjer HJ, Jeekel J, et al. Long-term prognostic value of preoperative anemia in patients with colorectal cancer: a systematic review and meta-analysis. Surgical Oncology. 2017;26(1):96-104.

30. Huang $X-z$, Yang Y-c, Chen Y, Wu C-c, Lin R-f, Wang Z-n, et al. Preoperative anemia or low hemoglobin predicts poor prognosis in gastric cancer patients: a meta-analysis. Disease markers. 2019;2019.

31. Dachs G, Tozer G. Hypoxia modulated gene expression: angiogenesis, metastasis and therapeutic exploitation. European Journal of Cancer. 2000;36(13):1649-60.

32. Vaupel $P$, Thews $O$, Hoeckel $M$. Treatment resistance of solid tumors. Medical oncology. 2001;18(4):243-59.

33. Semenza GL. Hypoxia, clonal selection, and the role of HIF-1 in tumor progression. Critical reviews in biochemistry and molecular biology. 2000;35(2):71-103.

34. Ludwig $H$, Van Belle $S$, Barrett-Lee $P$, Birgegård $G$, Bokemeyer C, Gascón P, et al. The European Cancer Anaemia Survey (ECAS): a large, multinational, prospective survey defining the prevalence, incidence, and treatment of anaemia in cancer patients. European journal of cancer. 2004;40(15):2293-306.

35. Khorana AA, Francis CW, Blumberg N, Culakova E, Refaai MA, Lyman GH. Blood transfusions, thrombosis, and mortality in hospitalized patients with cancer. Archives of internal medicine. 2008;168(21):2377-81.

36. Reim D, Strobl AN, Buchner C, Schirren R, Mueller W, 
Luppa P, et al. Perioperative transfusion of leukocyte depleted blood products in gastric cancer patients negatively influences oncologic outcome: a retrospective propensity score weighted analysis on 610 curatively resected gastric cancer patients. Medicine. 2016;95(29).

37. Xue L, Chen X-L, Wei-Han Z, Yang K, Chen X-Z, Zhang B, et al. Impact of perioperative blood transfusion on postoperative complications and prognosis of gastric adenocarcinoma patients with different preoperative hemoglobin value. Gastroenterology Research and Practice. 2016;2016.

38. Liu X, Qiu H, Huang Y, Xu D, Li W, Li Y, et al. Impact of preoperative anemia on outcomes in patients undergoing curative resection for gastric cancer: a single-institution retrospective analysis of 2163 Chinese patients. Cancer medicine. 2018;7(2):360-9.

39. Shen JG, Cheong JH, Hyung WJ, Kim J, Choi SH, Noh SH. Pretreatment anemia is associated with poorer survival in patients with stage I and II gastric cancer. Journal of surgical oncology. 2005;91(2):126-30. 